\title{
Physical activity dimensions after stroke: patterns and relation with lower limb motor function
}

Hanneke E. M. Braakhuis ${ }^{1,3,4^{*}}$ (D, Monique A. M. Berger ${ }^{4}$, Ruben G. R. H. Regterschot ${ }^{1,5}$, Erwin E. H. van Wegen ${ }^{6}$, Ruud W. Selles ${ }^{1,2}$, Gerard M. Ribbers ${ }^{1,3}$ and Johannes B. J. Bussmann ${ }^{1,3}$ on behalf of the PROFITS research group

\begin{abstract}
Background: Stroke survivors show deteriorated physical functioning and physical activity levels. Physical activity levels of stroke survivors are generally low. It is increasingly recognized that physical activity is a multidimensional construct that cannot be captured in a single outcome. In-depth insight into multidimensional physical activity patterns may guide the development and timing of targeted rehabilitation interventions. This longitudinal cohort study explored how multidimensional physical activity outcomes develop during recovery in the subacute phase after stroke and if changes in physical activity were correlated to recovery of lower limb motor function.
\end{abstract}

Methods: Patients were recruited during inpatient rehabilitation. At 3, 12, and 26 weeks post-onset, motor function was measured by the Fugl-Meyer Lower Extremity Assessment (FMA-LE). Physical activity was measured with the Activ8 accelerometer in multiple outcomes: counts per minute during walking (CPM walking; a measure of Intensity), number of active bouts (Frequency), mean length of active bouts (Distribution) and \% of waking time in upright positions (Duration). Generalized estimating equations (GEE) were used to study changes in physical activity over time and the relation with the change in lower limb motor recovery.

Results: Thirty-nine patients (age 56 $\pm 9,77 \%$ male, $89 \%$ ischemic stroke) were included. GEE models showed a significant main effect of time for PA Intensity $(+13 \%, p=0.007)$ and Duration $(+64 \%, p=0.012)$ between 3 and 12 weeks. Motor function did not show a significant effect in all PA models across the 3 timepoints $(p>0.020)$. A significant interaction effect of time $\times$ motor function was observed $(p<0.001)$.

Conclusions: Patterns of PA recovery depend on the PA dimensions: PA Intensity and Duration increased mostly between 3 and 12 weeks post-stroke, whereas Frequency and Distribution did not show substantial changes. Further, no strong associations with motor recovery and high inter-individual variability were documented, which underlies the need to consider factors specific to the disease, the individual patient and the context.

Keywords: Stroke, Motor function, Physical activity, Accelerometry

\footnotetext{
*Correspondence: h.braakhuis@erasmusmc.nl

${ }^{1}$ Department of Rehabilitation Medicine and Physical Therapy, Erasmus

MC University Medical Center, PO Box 2040, 3000 CA Rotterdam, The Netherlands

Full list of author information is available at the end of the article
}

\section{Introduction}

Approximately two-thirds of stroke survivors experience physical functioning problems, resulting in low levels of participation in physical activity (PA) $[1,2]$. Pursuing a physically active lifestyle is important because it reduces the risk for recurrent strokes, and it is linked to better functional capacity, quality of life, 
and overall life satisfaction [3, 4]. Therefore, from very early on post-stroke, one of the rehabilitation targets is optimizing patients' levels of PA [5-7].

In the last decade, objective measurement of PA is increasingly used in stroke studies, with accelerometry as the dominant technology [8]. Although accelerometry is relatively simple in itself, the interpretation and comparison of data are complex due to variable methods and devices. In addition, multiple outcome measures are reported, affecting the conclusions [8-10]. For example, Sanchez et al. [11] reported the mean duration of walking bouts after stroke and showed that it did not differ from healthy controls. In contrast, other studies showed that the average walking time and the daily number of steps were significantly lower in stroke survivors [11-13]. It is increasingly recognized that PA is multidimensional, including dimensions such as Intensity, Frequency, Duration and Distribution [8, 10, 14]. Therefore, clinically relevant information on PA cannot be captured in one outcome and reporting multiple outcomes concurrently preferred $[8,10,15]$.

Longitudinal studies describing changes in multiple dimensions of PA post-stroke are scarce. Two longitudinal studies found different patterns of multiple dimensions, for example; frequency and time in short, long, low and moderate intensity bouts $[16,17]$. Both studies started their measurements after discharge from rehabilitation, between 3 weeks and 4 months post-stroke. However, especially in the subacute phase (between 7 days and 6 months), measurements at fixed time points post-stroke are recommended due to the timing of several biological recovery processes [18]. Insight into the multidimensional PA patterns within the subacute phase is needed since it may guide appropriate timing and development of targeted interventions in rehabilitation [19-21].

PA patterns after stroke may be influenced by the level of motor recovery of a patient, since the performance of daily activities, such as walking, requires sufficient motor function, which is dependent on synergies [22]. However, a cross-sectional study showed no association between motor function and selfreported PA [23]. To date, it is unknown what the longitudinal relation is between motor function and PA measured in multiple dimensions with accelerometry. This longitudinal cohort study explored how multidimensional physical activity outcomes develop during recovery in the early and late subacute phase after stroke and how this related to changes in motor recovery.

\section{Methods}

\section{Study design and participants}

This is a longitudinal observational cohort study. Patients were included $<3$ weeks post stroke in this sub-study from Rijndam Rehabilitation (Rotterdam, The Netherlands) if they suffered from an ischemic or hemorrhagic stroke with a paretic arm or leg (defined as NIHSS $5 \mathrm{~A} / \mathrm{B}$ or $6 \mathrm{~A} / \mathrm{B} 4 \geq$ score $>0$ ). Other inclusion criteria were (i) 18 years or older, (ii) a Mini Mental State Examination (MMSE) score $>19$, and (iii) ability to sit at least 30 min with back support. Patients were screened by a trained research assistant between September 2016 and June 2019. All patients included in this study received the usual inpatient rehabilitation care program at Rijndam Rehabilitation. All patients gave their written informed consent, and the study was approved by the Medical Ethics Committee of Erasmus MC University Medical Center Rotterdam, The Netherlands (MEC-2015-687).

\section{Procedures}

Measurements were conducted at three fixed time points post-stroke; 3 (T1), 12 (T2) and 26 weeks (T3) [24]. Demographic and clinical characteristics were collected at the time of inclusion. At each time point, a trained assessor conducted all tests. During the first measurement (T1), patients were visited during inpatient rehabilitation; The measurements at 12 and 26 weeks took place during either inpatient or outpatient rehabilitation or at home. If a patient was discharged from inpatient services, the patient was visited at home.

\section{Measures \\ Motor function}

Motor function was determined by the Fugl Meyer Lower Extremity Assessment (FMA-LE) administered at 3, 12, and 26 weeks post-stroke [25]. The FMA-LE assesses motor function of the lower extremity based on diverse tasks, concerning reflex activity, movement within and outside synergy patterns, speed and coordination. The FMA-LE consists of 17 items, with a maximum score of 34 points. Each item was scored on a 3 -point scale $(0=$ cannot perform, $1=$ can partially perform, $2=$ can fully perform). A higher score represents a higher level of motor function.

\section{Physical activity}

PA was measured by the Activ8, which is a small $(30 * 32 * 10 \mathrm{~mm})$ and light-weight $(20 \mathrm{~g})$ triaxial accelerometer that can validly and continuously measure daily PA of individuals after stroke [26]. The Activ8 was 
attached to the front of the thigh of the non-affected leg of the patient with TegadermTM skin tape. This waterproof attachment allowed patients to swim and shower while wearing the device. The patients wore the Activ8 for 7 consecutive days. In addition to the PA monitoring, the participants were asked to report waking hours each day in a logbook to check whether this corresponded with the registration by the Activ8. PA assessments were considered valid if data from at least $10 \mathrm{~h}$ of waking hours per day were available over 5 days [27].

The output of the Activ8 monitor consists of time spent in six categories of body postures and movements (lying, sitting, standing, walking, running and cycling) within an epoch length of $30 \mathrm{~s}$ [14]. In each epoch, the number of movement counts is calculated for each category, representing the amount of movement within that epoch. The movement intensity van be calculated for each category, by dividing the number of movement counts by the time spent in a category. Standing, walking, running and cycling were merged into upright activities, while the same activities minus standing were classified as active activities. If a 30-s epoch consisted of $>80 \%$ of active activities, such an epoch was classified as active. If a time period of at least 4 subsequent active epochs occurred (i.e. a 2-min period at least), such a period was classified as an active bout.

Matlab R2014b was used to process the time and counts of the postures and movements into different outcomes representing four distinct dimensions of PA:

- Intensity counts per minute during walking $\left(\mathrm{CPM}_{\text {walking }}\right)$ [28]. Walking is the most common and important movement for stroke survivors in daily activities and participation in society [29-31].

- Frequency the number of active bouts (N Bout ${ }_{\text {active }}$ )

- Distribution the mean length of active bouts (ML Bout $_{\text {active }}$ ) represented the distribution of PA and was calculated by the sum of the length of all active bouts divided by the number of active bouts.

- Duration the relative time (\% Upright) in upright postures and movements represented duration of PA and was calculated by the sum of the duration in upright movements, divided by the total waking time multiplied by $100 \%$.

All outcome measures were averaged per day by dividing by the number of days that contained valid measurements.

\section{Statistical analyses}

Statistical analyses were performed in RStudio (version 1.2.50001, RStudio, Inc.). Baseline characteristics, motor function and PA outcomes were described by means and standard deviations with minimal and maximal values for continuous variables and frequencies and percentages for categorical variables.

Marginal modelling with Generalized Estimating Equations (GEE) was used to detect longitudinal changes since it controls for correlations between repeated measurements [32]. All four PA outcomes were used as dependent variables in the GEE models. Time was set as an independent factor with three levels (3, 12, 26 weeks). For all models, an identity link function was used according to the distribution of the PA outcomes. The choice of the most suitable working correlation matrix was based on the lowest quasi-likelihood under the independence model criteria (QIC) [32].

First, to detect changes in multidimensional PA over time, a univariate GEE model with only time as a predictor was developed for each PA outcome. After that, to investigate the relation with motor recovery, other multivariate GEE models, including time, motor function and an interaction between time and motor function were developed. The interaction term assessed the association between PA outcomes and changes in motor function over time. These GEE models were conducted with stepwise approach; first, a full model was developed with time, motor function and the interaction between time and motor function. Second, if the interaction term showed no added value, it was deleted from the model.

Since PA is measured in four domains, we used Bonferroni for correcting for multiple testing, considering $\mathrm{p}<0.0125$ as significant. If a significant main effect of time was observed, post-hoc comparisons with a Bonferroni correction was conducted. Post-hoc analyses were considered significant at $\mathrm{p}<0.05$.

\section{Results \\ Participants}

Figure 1 shows the flow of inclusion of patients. Sixtytwo patients accepted informed consent. Twenty threepatients withdrew before or during the first measurement (T1) and were excluded. Reasons for withdrawing were amongst others; withrew from study due personal reasons, wrong diagnosis, hospitalization, and early discharge. Thirty-nine patients were included in further analyses. The number of valid measurements that were included in the analysis was $\mathrm{n}=30$ at $\mathrm{T} 1, \mathrm{n}=28$ at $\mathrm{T} 2$ and $n=24$ at T3. Baseline characteristics of the patients within the study sample at baseline $(n=39)$ are shown in Table 1.

\section{Longitudinal changes of physical activity}

The mean waking time used for Activ8 measurements was $14 \mathrm{~h} 19 \mathrm{~min} \pm 1 \mathrm{~h} 6 \mathrm{~min}$ per day. Figure 2 shows PA changes per individual and mean change of the sample. 
PROFITS patients screened for activity monitoring $=107$

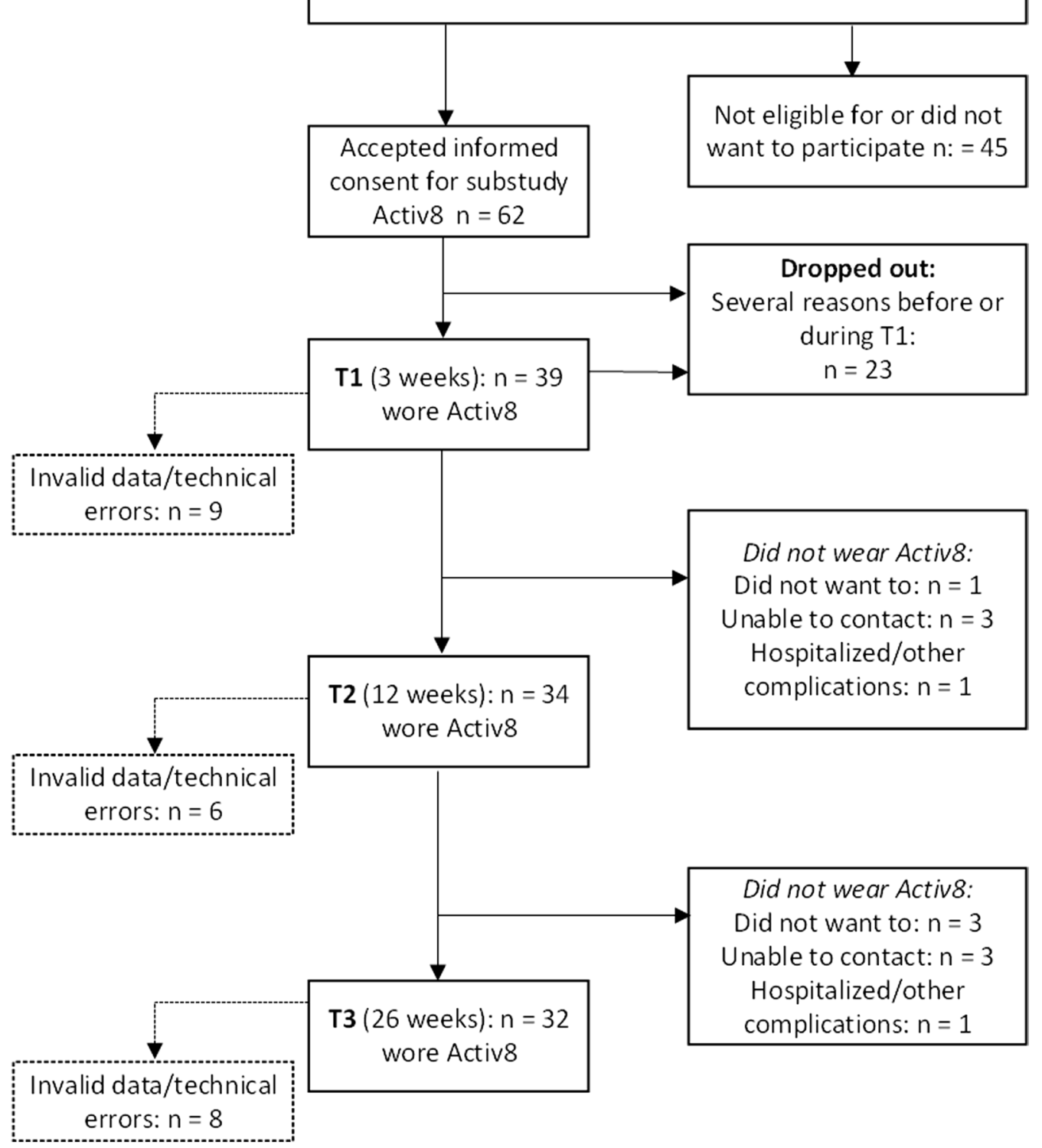

Fig. 1 Flowchart of inclusion of patients

Additionally, Fig. 2 shows the results of the univariate GEE models with only time as a predictor. After Bonferroni correction, a main effect of time was observed for PA intensity $(\mathrm{p}=0.007)$ and PA duration $(\mathrm{p}=0.001)$ but not for PA frequency $(\mathrm{p}=0.660)$ and distribution $(\mathrm{p}=0.035)$. Post-hoc analyses showed a significant increase $(+13 \%)$ of PA intensity between 3 and 12 weeks $(\mathrm{p}=0.005)$ and significant increase $(+64 \%)$ of PA duration between 3 and 12 weeks $(\mathrm{p}=0.032)$.
Longitudinal relation between physical activity and motor function

Average FMA-LE at 3 weeks was $22 \pm 10$, at 12 weeks $27 \pm 7$ and at 26 weeks $27 \pm 6$. Table 2 shows the results of the four multivariate GEE models, including time, motor function and time $\times$ motor function. In the multivariate GEE analyses, main effects of time were observed in the PA intensity $(\mathrm{p}=0.007)$ and duration $(\mathrm{p}=0.001)$ model (Table 2). Post-hoc analyses between time points showed a significant effect for duration between 3 vs. 26 weeks 
Table 1 Baseline characteristics of patients included in Activ8 measurements $(\mathrm{N}=39)$

Age (years, mean $\pm S D$, min-max)

$56 \pm 9(37-75)$

Sex (male $n, \%$ )

Type of stroke (hemorrhagic/ischemic, n, \%ischemic)

$30,77 \%$

Time between stroke and admission to inpatient rehabilitation (days mean $\pm \mathrm{SD}$, min-max)

Length of inpatient rehabilitation (days, mean $\pm S D$, min-max)

Barthel Index (mean $\pm S D$, min-max)

$4 / 35,90 \%$

$11 \pm 6(0-22)$

$59 \pm 34(9-120)$

Motricity Index Lower Extremity (mean \pm SD, min-max)

Berg Balance Scale (mean $\pm S D$, min-max)

$15 \pm 4(7-20)$

$64 \pm 29(0-100)$

$36 \pm 16(4-56)$

Fugl Meyer lower extremity (mean $\pm S D$, min-max)

$(\mathrm{p}<0.021)$. No effect $(\mathrm{p}<0.013)$ for motor function was observed in all PA models (PA Intensity; $p=0.032$, Frequency; $\mathrm{p}=0.020$, Distribution; $\mathrm{p}=0.021$, Duration; $\mathrm{p}=0.121)$.

\section{Discussion}

This study showed that PA Intensity and Duration improved between three and twelve weeks post stroke whereas PA Frequency and Distribution did not show significant change during the subacute phase after stroke. Overall, the relation with motor recovery was absent or weak. In all PA dimensions, high inter-individual variability, both cross-sectional and over time was observed.

It is generally known that the most considerable improvement in post-stroke physical functioning is by spontaneous recovery occurring most strongly within the first 5 to 6 weeks, and by intensive rehabilitation therapy within the first 3 months post stroke $[5,19]$. Our study showed significant improvements in PA Intensity and PA Duration from 3 to 12 weeks post-stroke, with a plateau thereafter. In other words, patients increased spending time upright and walked more intensively. PA Intensity, measured by accelerometercounts during walking, indicates walking speed, and has been shown a sensitive measure for detecting clinically important changes $[28,33]$. In contrast, no increase was observed in the
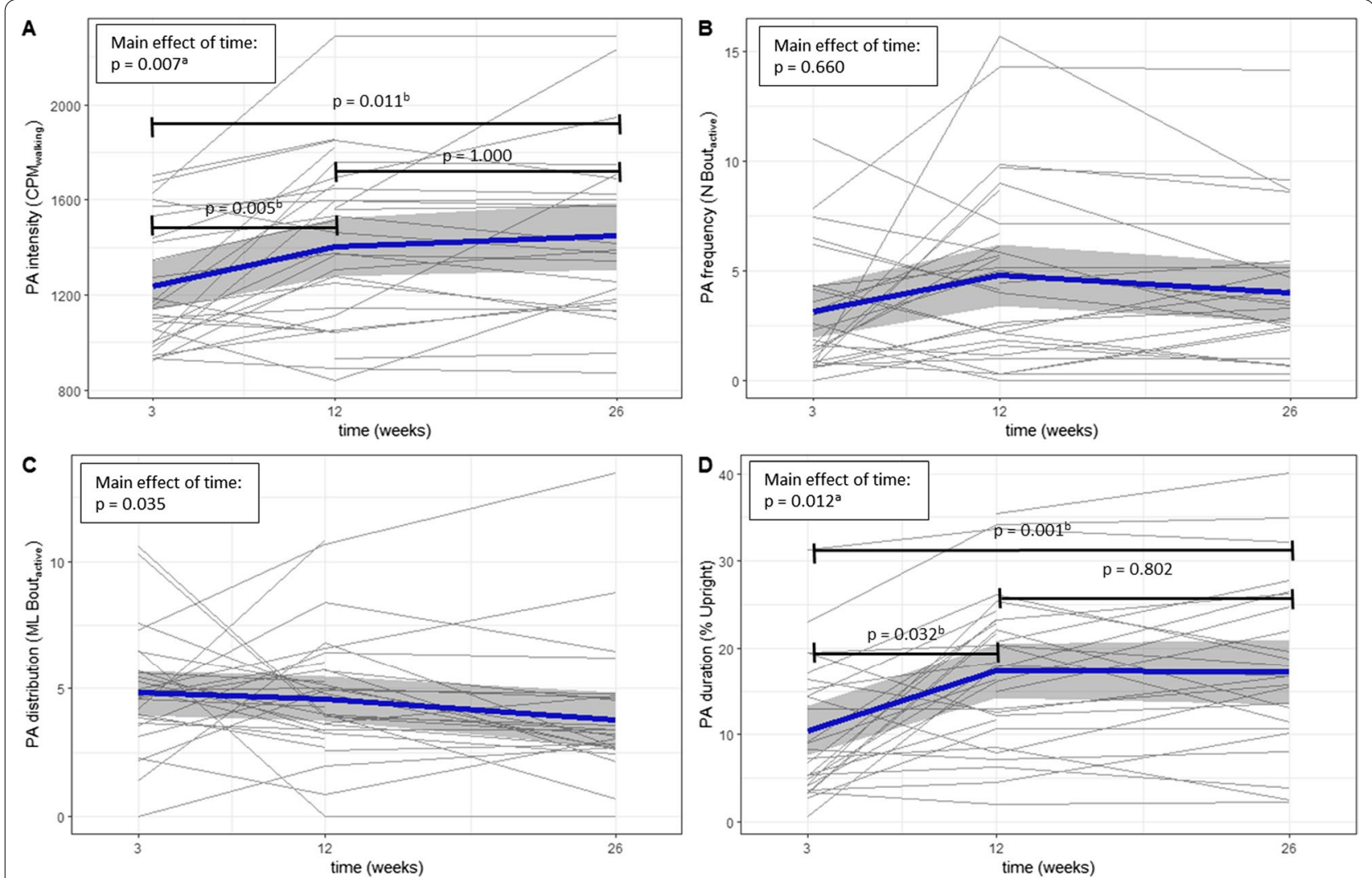

Fig. 2 Individual and mean changes of physical activity (PA) intensity, frequency, distribution and duration from 3 to 26 weeks post-stroke with p-values of of post-hoc analyses between time points from the univariate generalized estimating equations (GEE) models. NOTE: Grey lines represent PA of individuals, blue lines represent mean PA and grey band represent $95 \% \mathrm{Cl}^{\mathrm{a}}{ }^{\mathrm{a}}<0.0125$ for main effect, ${ }^{b} \mathrm{p}<0.050$ for post-hoc analyses between time points 
Table 2 Results of multidimensional physical activity (PA) in the multivariate generalized estimating equations (GEE) models with post hoc analyses between 3 vs. 12.3 vs. 26 and 12 vs. 26 weeks post-stroke

\begin{tabular}{|c|c|c|c|c|c|c|c|}
\hline & \multirow[t]{2}{*}{$\beta$} & \multirow[t]{2}{*}{ SE } & \multirow[t]{2}{*}{ p-value } & \multirow{2}{*}{$\begin{array}{l}p \text {-value of the main } \\
\text { effect of time }\end{array}$} & \multicolumn{3}{|c|}{ Post-hoc between time points, $p$-value } \\
\hline & & & & & 3 vs. 12 weeks & 3 vs. 26 weeks & 12 vs. 26 weeks \\
\hline \multicolumn{8}{|l|}{ PA intensity $\left(\mathrm{CPM}_{\text {walking }}{ }^{\left.* 10^{3}\right)}\right.$} \\
\hline Time (12 weeks) & 176 & 853 & 0.040 & $0.007^{\mathrm{a}}$ & 0.118 & 0.254 & 1.000 \\
\hline Time (26 weeks) & 153 & 887 & 0.085 & & & & \\
\hline FMA-LE & 10.7 & 498 & 0.032 & & & & \\
\hline \multicolumn{8}{|l|}{ PA Frequency (N Bout ${ }_{\text {active }}$ ) } \\
\hline Time (12 weeks) & -0.51 & 1.55 & 0.744 & 0.032 & - & - & - \\
\hline Time (26 weeks) & -1.21 & 1.21 & 0.318 & & & & \\
\hline FMA-LE & 0.17 & 0.07 & 0.020 & & & & \\
\hline \multicolumn{8}{|l|}{ PA distribution (ML Bout ${ }_{\text {active }}$ ) } \\
\hline Time (12 weeks) & -5.88 & 1.78 & $0.001^{\mathrm{a}}$ & 0.035 & - & - & - \\
\hline Time (26 weeks) & -7.12 & 1.80 & $<0.001^{\mathrm{a}}$ & & & & \\
\hline FMA-LE & -0.11 & 0.05 & 0.021 & & & & \\
\hline Time (12 weeks) × FMA-LE & 0.22 & 0.07 & $0.001^{\mathrm{a}}$ & & & & \\
\hline Time ( 26 weeks) $\times$ FMA-LE & 0.23 & 0.07 & $0.001^{\mathrm{a}}$ & & & & \\
\hline \multicolumn{8}{|l|}{ PA duration (\% Upright) } \\
\hline Time (12 weeks) & 4.83 & 2.47 & 0.051 & $0.001^{\mathrm{a}}$ & 0.153 & $0.021^{b}$ & 1.000 \\
\hline Time (26 weeks) & 5.91 & 2.20 & $0.007^{\mathrm{a}}$ & & & & \\
\hline FMA-LE & 0.24 & 0.15 & 0.121 & & & & \\
\hline
\end{tabular}

PA physical activity, FMA-LE Fugl Meyer Assessment Lower Extremity as a measure of motor function, $n / a$ not applicable

${ }^{a} \mathrm{p}<0.013$ for main effect

${ }^{\mathrm{b}} \mathrm{p}<0.050$ for post-hoc analyses between time points

bout-specific outcomes of PA Frequency (bout number) or PA Distribution (bout length), suggesting that the passage of time after stroke did not lead to more persistent and prolonged physical activities of two minutes or more. Therefore, it seems that the evaluation of temporal PA changes is sensitive to the selected outcome measure, which is in line with the results of Mahendran et al. [16]. Since until now, no consensus on the best post-stroke PA measures has been recommended [8], we recommend measuring and reporting multiple dimensions of PA. Besides giving a complete overview of patients' PA, it will also contribute to a better understanding and a wellgrounded selection of future outcomes that are sensitive to change post stroke.

Only the PA Distribution model showed significant interaction effects between motor function and time at 12 weeks and 26 weeks after stroke, meaning that patients with increasing motor function seem to be more persistent in uninterrupted activity as time progresses. However in general, no or at best weak associatons between PA en motor function were found in the multivariate GEE models. One explanation is that overall, the FMA-LE scores in our study sample were relatively high, and the changes over time relatively small.
At three weeks, mean FMA-LE was $22 \pm 10$. According to Kwong et al. [34], a score of 21 or higher represents a high level of motor function in stroke survivors. It is possible that for these patients, substantial spontaneous recovery occurred before the first measurement and no large nor clinically relevant FMA-LE changes were taken into account in our longitudinal analysis. FMA-LE may not be sensitive enough to detect small increments in motor function in patients with a relatively high level of motor function. Also, learned compensatory strategies to overcome motor impairments might have distorted the relationship [35]. The weak relationship between physical activity and motor recovery supports the importance of collecting objective information on a patients' performance in their own context, such as accelerometer-based $\mathrm{PA}$, is relevant in addition to other clinical tests.

Another remarkable finding was large within and between-subject variability that was observed in our study (Fig. 2). To illustrate, the relative time spent in upright positions at 26 weeks after stroke ranged from 1 to $40 \%$ of the day, representing eight minutes a day to more than five hours. Comparable ranges were found in PA intensity, frequency and distribution. This variability might be the result of the varying demographics, 
functional level (Table 1), and other factors such as cognitive impairments, and pre-stroke lifestyle, physical and social environment [23]. The high intra-individual variability underscores the urge for an individual approach in rehabilitation research and practice $[5,36]$.

Unique in our study was the measurements at fixed time points post onset aligned with the underlying recovery mechanisms of body structures and functions [24]. In contrast, other longitudinal PA studies $[16,17]$ measured at time points relative to time of admission to or discharge from rehabilitation, reflecting a process of care [18]. Future research should reveal if measurements of PA changes based on both approaches differ and what is most informative for appropriate timing of interventions. To date, optimal timing of interventions after stroke is still a challenge $[18,21]$.

Although similar to earlier studies on post-stroke PA $[16,37,38]$, a limitation of this study was the relatively small sample size. Therefore, the results of the regression models should be interpreted with caution. Another limitation was the amount of missing data resulting from device failures and subject compliance. Future developments-e.g., smaller sensors, body posture and movement detection from wrist-worn devices-might improve compliance in future studies. Nevertheless, GEE analyses appropriately handles at-random missing data. Also, the choice of outcome measures may have influenced our results. To the best of our knowledge, we chose four theoretically different physical activity measures that are still easy to interpret from many available possibilities.

\section{Conclusion}

Our study showed that patterns of PA recovery depend on the PA dimensions: PA Intensity and Duration increased mostly between three and twelve weeks poststroke, whereas Frequency and Distribution did not show substantial changes. Further, we observed high inter-individual variability and no, or at best weak associations between PA dimensions and motor recovery. The observed differences in PA patterns underline the importance of capturing multiple PA dimensions and considering factors specific to the disease, the individual patient and the context.

\footnotetext{
Acknowledgements

This study was performed on behalf of the PROFITS research group: Amsterdam group: Dr Carel Meskers, MD (projectleader) Amsterdam UMC, Vrije Universiteit Amsterdam, Department of Rehabilitation Medicine, Amsterdam Movement Sciences, Amsterdam Neuroscience, Amsterdam, the Netherlands; Department of Physical Therapy and Human Movement Sciences, Feinberg School of Medicine, Northwestern University, Chicago, IL, United States; Prof. Dr. Gert Kwakkel (steering team member), Amsterdam UMC, Vrije Universiteit Amsterdam, Department of Rehabilitation Medicine, Amsterdam Movement Sciences, Amsterdam Neuroscience, de Boelelaan 1117, Amsterdam, the Netherlands, Department of Physical Therapy and Human Movement Sciences, Feinberg School of Medicine, Northwestern University, Chicago, IL,
}

United States, Department of Neurorehabilitation, Amsterdam Rehabilitation Research Centre, Reade, Amsterdam, the Netherlands; Dr. Erwin E.H. van Wegen (steering team member), Department of Rehabilitation Medicine, Amsterdam Neuroscience and Amsterdam Movement Sciences, Amsterdam UMC, Vrije Universiteit Amsterdam, Amsterdam, The Netherlands.; Dr. Rinske Nijland, (co-researcher and responsible for data collection) Department of Neurorehabilitation, Amsterdam Rehabilitation Research Centre, Reade, Amsterdam, Netherlands; Drs. Aukje Andinga, (co-researcher) Amsterdam University Medical Centers, Vrije Universiteit Amsterdam, Department of Rehabilitation Medicine, Amsterdam Movement Sciences, Amsterdam Neuroscience, Amsterdam, the Netherlands; Dr. Valentijn Zonjee, Department of Neurology, Onze Lieve Vrouwe Gasthuis (O.L.V.G.), Amsterdam, the Netherlands, Dr. Sander van Schaik, Department of Neurology, Onze Lieve Vrouwe Gasthuis (O.L.V.G.), Amsterdam, the Netherlands; Drs. Muriel Koolstra-Rutgers (co-researcher), Amsterdam UMC, Vrije Universiteit Amsterdam, Department of Rehabilitation Medicine, Amsterdam Movement Sciences, Amsterdam Neuroscience, Amsterdam, the Netherlands; Prof. Dr. Renske van den Berg-Vos, Department of Neurology, Onze Lieve Vrouwe Gasthuis (O.L.V.G.), Amsterdam, the Netherlands, Department of Neurology, Amsterdam UMC, University of Amsterdam, Amsterdam Neuroscience, Amsterdam, The Netherlands. Rotterdam group: Dr. Ruud Selles, (co-project leader), Department of Plastic, Reconstructive and Hand Surgery, Erasmus MC, University Medical Center Rotterdam, Rotterdam, The Netherlands; Department of Rehabilitation Medicine, Erasmus MC, University Medical Center Rotterdam, Rotterdam, The Netherlands; Dr. Jorrit Slaman, (steering group), Rijndam Rehabilitation Center, Rotterdam, Netherlands; Prof. Dr. Gerard Ribbers (clinical lead), Department of Rehabilitation Medicine, Erasmus MC, University Medical Center Rotterdam, Rotterdam, The Netherlands, Rijndam Rehabilitation Center, Rotterdam, Netherlands; Dr. Harm Slijper (data collection advisor), Department of Plastic, Reconstructive and Hand Surgery, Erasmus MC, University Medical Center Rotterdam, Rotterdam, Hand and Wrist Centre, Xpert Clinic, Hilversum, The Netherlands; Jeanne Bakx (data analysis), Hand and Wrist Centre, Xpert Clinic, Hilversum, The Netherlands; Jeffrey Visser (data collection design), Department of Plastic, Reconstructive and Hand Surgery, Erasmus MC, University Medical Center Rotterdam, Rotterdam, The Netherlands; Sylvia Gorter, Department of Rehabilitation Medicine, Erasmus MC, University Medical Center Rotterdam, Rotterdam, The Netherlands;| Dr. Hans Bussmann (responsible for subproject activity monitoring); Department of Rehabilitation Medicine, Erasmus MC, University Medical Center Rotterdam, Rotterdam, The Netherlands; Hanneke Braakhuis, PhD student activity monitoring (subproject Profits), Department of Rehabilitation Medicine, Erasmus MC, University Medical Center Rotterdam, Rotterdam, The Netherlands, Faculty of Health, Nutrition and Sport, The Hague University of Applied Sciences, The Hague, The Netherlands.

\section{Authors' contributions}

$\mathrm{HBr}$ contributed to the design, data collection of the activity monitor, statistical analysis, writing the manuscript and interpretation of the data for this study. MB contributed to the design, interpretation of the data and manuscript review. EvW, RS, RR and GR contributed to manuscript review, interpretation of the data and the design and data-collection of the study. JB contributed to the design, writing of the manuscript, interpretation of the data and the design and data collection. The PROFITS research group contributed to the design and data-collection of the PROFITS study, and supervision of the PROFITS study progress. All authors read and approved the final manuscript.

\section{Funding}

The PROFITS study is supported by ZonMW project 104003014, titled 'PROFITS - Precision profiling to improve long-term outcome after stroke'.

Availability of data and material

The datasets generated and/or analysed during the current study are currently not publicly available due other PROFITS studies that are still in progress.

\section{Declarations}

\section{Ethics approval and consent to participate}

The protocol for this study was approved by the Medical Ethics Committee of Erasmus MC University Medical Center Rotterdam, The Netherlands and informed consent was provided by all participants. 


\section{Consent for publication \\ Not applicable.}

\section{Competing interests}

The authors declare that they have no competing interests.

\begin{abstract}
Author details
'Department of Rehabilitation Medicine and Physical Therapy, Erasmus MC University Medical Center, PO Box 2040, 3000 CA Rotterdam, The Netherlands. ${ }^{2}$ Department of Plastic and Reconstructive Surgery, Erasmus MC University Medical Center, Rotterdam, The Netherlands. ${ }^{3}$ Rijndam Rehabilitation, Rotterdam, The Netherlands. ${ }^{4}$ Faculty of Health, Nutrition and Sport, The Hague University of Applied Sciences, The Hague, The Netherlands. ${ }^{5}$ Department of Biomedical Signals and Systems, University of Twente, Enschede, The Netherlands. ${ }^{6}$ Department of Rehabilitation Medicine, Amsterdam Neuroscience and Amsterdam Movement Sciences, Amsterdam UMC, Vrije Universiteit Amsterdam, Amsterdam, The Netherlands.
\end{abstract}

Received: 1 April 2021 Accepted: 19 November 2021

Published online: 11 December 2021

\section{References}

1. Shaughnessy M, Michael KM, Sorkin JD, Macko RF. Steps after stroke: capturing ambulatory recovery. Stroke. 2005;36(6):1305-7.

2. Baer HR, Wolf SL. Modified emory functional ambulation profile: an outcome measure for the rehabilitation of poststroke gait dysfunction. Stroke. 2001;32(4):973-9.

3. Billinger SA, Arena R, Bernhardt J, Eng JJ, Franklin BA, Johnson CM, et al. Physical activity and exercise recommendations for stroke survivors: a statement for healthcare professionals from the American Heart Association/American Stroke Association. Stroke. 2014;45(8):2532-53.

4. Hartman-Maeir A, Soroker N, Ring H, Avni N, Katz N. Activities, participation and satisfaction one-year post stroke. Disabil Rehabil. 2007;29(7):559-66.

5. Langhorne P, Bernhardt J, Kwakkel G. Stroke rehabilitation. Lancet. 2011;377(9778):1693-702.

6. Wu WX, Zhou CY, Wang ZW, Chen GQ, Chen XL, Jin HM, et al. Effect of early and intensive rehabilitation after ischemic stroke on functional recovery of the lower limbs: a pilot, randomized trial. J Stroke Cerebrovasc Dis. 2020;29(5):104649.

7. Hu MH, Hsu SS, Yip PK, Jeng JS, Wang YH. Early and intensive rehabilitation predicts good functional outcomes in patients admitted to the stroke intensive care unit. Disabil Rehabil. 2010;32(15):1251-9.

8. Fini NA, Holland AE, Keating J, Simek J, Bernhardt J. How is physical activity monitored in people following stroke? Disabil Rehabil. 2015:37(19):1717-31.

9. English C, Healy GN, Coates A, Lewis L, Olds T, Bernhardt J. Sitting and activity time in people with stroke. Phys Ther. 2016:96(2):193-201.

10. Bassett DR, Troiano RP, McClain JJ, Wolff DL. Accelerometer-based physical activity: total volume per day and standardized measures. Med Sci Sports Exerc. 2015;47(4):833-8.

11. Sánchez MC, Bussmann J, Janssen W, Horemans H, Chastin S, Heijenbrok $M$, et al. Accelerometric assessment of different dimensions of natural walking during the first year after stroke: recovery of amount, distribution, quality and speed of walking. J Rehabil Med. 2015:47(8):714-21.

12. Paul L, Brewster S, Wyke S, Gill JM, Alexander G, Dybus A, et al. Physical activity profiles and sedentary behaviour in people following stroke: a cross-sectional study. Disabil Rehabil. 2016;38(4):362-7.

13. Moore SA, Hallsworth K, Plötz T, Ford GA, Rochester L, Trenell MI. Physical activity, sedentary behaviour and metabolic control following stroke: a cross-sectional and longitudinal study. PLOS ONE. 2013;8(1):e55263.

14. Braakhuis HEM, Roelofs JMB, Berger MAM, Ribbers GM, Weerdesteyn V, Bussmann JBJ. Intensity of daily physical activity_a key component for improving physical capacity after minor stroke? Disabil Rehabil. 2020;15:1-6.

15. Braakhuis HEM, Berger MAM, van der Stok GA, van Meeteren J, de Groot $\mathrm{V}$, Beckerman $\mathrm{H}$, et al. Three distinct physical behavior types in fatigued patients with multiple sclerosis. J Neuroeng Rehabil. 2019;16(1):105.
16. Mahendran N, Kuys SS, Brauer SG. Recovery of ambulation activity across the first six months post-stroke. Gait Posture. 2016;49:271-6.

17. Wondergem R, Veenhof C, Wouters EMJ, de Bie RA, Visser-Meily JMA, Pisters MF. Movement behavior patterns in people with first-ever stroke. Stroke. 2019:50(12):3553-60.

18. Bernhardt J, Hayward KS, Kwakkel G, Ward NS, Wolf SL, Borschmann K, et al. Agreed definitions and a shared vision for new standards in stroke recovery research: the stroke recovery and rehabilitation roundtable taskforce. Neurorehabil Neural Repair. 2017:31(9):793-9.

19. Verheyden G, Nieuwboer A, De Wit L, Thijs V, Dobbelaere J, Devos H, et al. Time course of trunk, arm, leg, and functional recovery after ischemic stroke. Neurorehabil Neural Repair. 2008;22(2):173-9.

20. Toschke AM, Tilling K, Cox AM, Rudd AG, Heuschmann PU, Wolfe CD. Patient-specific recovery patterns over time measured by dependence in activities of daily living after stroke and post-stroke care: the South London Stroke Register (SLSR). Eur J Neurol. 2010;17(2):219-25.

21. Huang HC, Chung KC, Lai DC, Sung SF. The impact of timing and dose of rehabilitation delivery on functional recovery of stroke patients. J Chin Med Assoc. 2009;72(5):257-64.

22. Roelofs J. Static and dynamic standing balance in the chronic phase after stroke: how to recover? [PhD-thesis]. Nijmegen: Radboud University Nijmegen; 2019.

23. Danielsson A, Willén C, Sunnerhagen KS. Physical activity, ambulation, and motor impairment late after stroke. Stroke Res Treat. 2012:2012:818513.

24. Kwakkel G, Lannin NA, Borschmann K, English C, Ali M, Churilov L, et al. Standardized measurement of sensorimotor recovery in stroke trials: consensus-based core recommendations from the Stroke Recovery and Rehabilitation Roundtable. Int J Stroke. 2017;12(5):451-61.

25. Fugl-Meyer AR, Jääskö L, Leyman I, Olsson S, Steglind S. The post-stroke hemiplegic patient. 1. A method for evaluation of physical performance. Scand J Rehabil Med. 1975;7(1):13-31.

26. Fanchamps MHJ, Horemans HLD, Ribbers GM, Stam HJ, Bussmann JBJ. The accuracy of the detection of body postures and movements using a physical activity monitor in people after a stroke. Sensors (Basel). 2018;18(7):1.

27. Trost SG, Mclver KL, Pate RR. Conducting accelerometer-based activity assessments in field-based research. Med Sci Sports Exerc. 2005:37(11 Suppl):S531-43.

28. Fridolfsson J, Börjesson M, Arvidsson D. A biomechanical re-examination of physical activity measurement with accelerometers. Sensors (Basel). 2018;18(10):3399.

29. Smith MC, Barber PA, Stinear CM. The TWIST algorithm predicts time to walking independently after stroke. Neurorehabil Neural Repair. 2017;31(10-11):955-64.

30. Trost SG, O'Neil M. Clinical use of objective measures of physical activity. Br J Sports Med. 2014;48(3):178-81.

31. Luo L, Zhu S, Shi L, Wang P, Li M, Yuan S. High intensity exercise for walking competency in individuals with stroke: a systematic review and meta-analysis. J Stroke Cerebrovasc Dis. 2019;28:104414.

32. Ballinger GA. Using generalized estimating equations for longitudinal data analysis. Organ Res Methods. 2004;7(2):127-50.

33. Kollen B, Kwakkel G, Lindeman E. Time dependency of walking classification in stroke. Phys Ther. 2006;86(5):618-25.

34. Kwong PWH, Ng SSM. Cutoff score of the lower-extremity motor subscale of Fugl-Meyer assessment in chronic stroke survivors: a cross-sectional study. Arch Phys Med Rehabil. 2019;100(9):1782-7.

35. van Meulen FB, Weenk D, van Asseldonk EH, Schepers HM, Veltink PH, Buurke JH. Analysis of balance during functional walking in stroke survivors. PLOS ONE. 2016;11(11):e0166789.

36. Louie DR, Bird ML, Menon C, Eng JJ. Perspectives on the prospective development of stroke-specific lower extremity wearable monitoring technology: a qualitative focus group study with physical therapists and individuals with stroke. J Neuroeng Rehabil. 2020;17(1):31.

37. Askim T, Bernhardt J, Churilov L, Fredriksen KR, Indredavik B. Changes in physical activity and related functional and disability levels in the first six months after stroke: a longitudinal follow-up study. J Rehabil Med. 2013;45(5):423-8.

38. Shimizu N, Hashidate H, Ota T, Yatsunami M. Daytime physical activity at admission is associated with improvement of gait independence 1 
month later in people with subacute stroke: a longitudinal study. Top Stroke Rehabil. 2020;27(1):25-32.

\section{Publisher's Note}

Springer Nature remains neutral with regard to jurisdictional claims in published maps and institutional affiliations.

Ready to submit your research? Choose BMC and benefit from:

- fast, convenient online submission

- thorough peer review by experienced researchers in your field

- rapid publication on acceptance

- support for research data, including large and complex data types

- gold Open Access which fosters wider collaboration and increased citations

- maximum visibility for your research: over 100M website views per year

At $\mathrm{BMC}$, research is always in progress.

Learn more biomedcentral.com/submissions 